\title{
Uso de aditivos biológicos na ensilagem de forrageiras
}

\author{
Use of biological addictive in ensiling of forage
}

\author{
Marcos Rogério Oliveira' \\ Mikael Neumann²(*) \\ Rodrigo Oliboni ${ }^{3}$ \\ Suelen Tulio de Córdova Gobetti ${ }^{4}$ \\ Marcos Ventura Faria ${ }^{5}$
}

\section{Resumo}

Os inoculantes biológicos por meio de microrganismo objetivam acelerar a queda do $\mathrm{pH}$, induzindo a exclusão competitiva de microrganismos indesejáveis, reduzindo a perda de nutrientes durante o metabolismo fermentativo e refermentativo. Os aditivos enzimáticos possuem principais atividades de catalase e hemicelulase. Já os bacterianos são culturas tanto homofermentativas, que são efetivos na produção de acido lático, quanto cepas heterofermentativas, que produzem além do ácido lático o ácido acético para auxiliar na estabilidade aeróbica. Resultados são controversos sobre os seus benefícios no decréscimo do $\mathrm{pH}$, no teor de nitrogênio amoniacal, na redução na fração fibrosa, na digestibilidade e consumo de matéria seca, indicando a existência de variação entre a natureza do inóculo biológico e a forragem a ser ensilada.

Palavras-chave: fibra em detergente neutro; matéria seca; $\mathrm{pH}$.

\section{Abstract}

The biological inoculants through microorganisms aim at accelerating the decrease of $\mathrm{pH}$, inducing the competitive exclusion of undesirable microorganisms, reducing

I MSc.; Médico Veterinário; Doutorando em Zootecnia na Universidade Estadual de Maringá, UEM; Maringá, Paraná, Brasil; E-mail: oliveira.marcos.r@gmail.com

2 Dr.; Engenheiro Agrônomo; Professor do Departamento de Medicina Veterinária na Universidade Estadual do Centro-Oeste, UNICENTRO; Endereço: Rua Simeão Camargo Varela de Sá, 03, CEP: 85040-080, Guarapuava, Paraná, Brasil; E-mail: mikaelneunamm@hotmail.com (*) Autor para correspondência.

3 MSc.; Engenheiro Agrônomo da OR Melhoramentos de Sementes Ltda; Passo Fundo, Rio Grande do Sul, Brasil; E-mail: roliboni@hotmail.com

4 MSc.; Médica Veterinária; Doutoranda em Ciência Animal na Universidade Estadual de Londrina, UEL; Londrina, Paraná, Brasil; E-mail: suellencordova@hotmail.com

5 Dr.; Engenheiro Agrônomo; Professor do Departamento de Agronomia da Universidade Estadual do Centro-Oeste, UNICENTRO; Guarapuava, Paraná, Brasil; Bolsista de Produtividade em Pesquisa do CNPq; E-mail:mfaria@unicentro.br 
the loss of nutrients during the fermentative metabolism. The enzyme addictives are the main activities of catalase and hemicellulase. On the other hand, the bacterial ones are homofermentatives cultures, which are effective in the production of lactic acid, and heterofermentatives stumps, that produce the lactic acid and also the acetic acid to aid the aerobics stability. The results are controversial on their benefits in decreasing the $\mathrm{pH}$, in the content of ammonium nitrogen, in the reduction in the fibrous fraction, in the digestibility and dry matter intake, indicating the variation existence between the nature of the biological inoculum and the forage to be ensiled.

Key words: neutral detergent fiber; dry matter; $\mathrm{pH}$.

\section{Introdução}

A ensilagem é um método de preservação de forragens baseado em acidificação resultante de processo fermentativo, onde o objetivo principal é maximizar a preservação de nutrientes (KUNG JR., 2009). Desse modo, Kung Jr. (2001) relatou que os inoculantes biológicos para silagem podem ser organizados em estimulantes da fermentação, que agem por meio de adição de culturas de microrganismos e propõe direcionar a fermentação e melhorar a característica nutricional da forragem ensilada. Segundo Bernardes (2006), esta classe de aditivos é a mais estudada e de mais rápido desenvolvimento atual no mundo.

Segundo Zopollatto et al. (2009) os inoculantes microbianos usados como aditivos incluem bactérias homofermentativas, heterofermentativas, ou a combinação destas. Todavia, resultados positivos nos parâmetro fermentativos nem sempre ficaram evidentes e há na literatura controvérsias históricas sobre o uso desses aditivos, em função de resultados inconstantes obtidos na sua utilização (KUNG JR. et al., 2003; MUCK, 2010).

Atualmente, com o avanço nas técnicas de fermentação, de liofilização e encapsulamento de cepas selecionadas tem sido propiciado o lançamento de novos produtos comerciais, com o intuito de melhorar a fermentação na ensilagem, estabilidade aeróbia e digestão da fibra. Dessa forma, aditivos heteroláticos vêm sendo desenvolvidos para reduzir os efeitos negativos da fermentação homolática (KUNG JR., 2009), uma vez que o ácido lático não é agente antimicótico e geralmente é utilizado como substrato na deterioração aeróbia (MUCK; KUNG JR., 1997), pois, problemas relacionados á estabilidade das silagens geraram buscas por microrganismos com características distintas daquelas antes desejadas (FILYA et al., 2004), visto que as perdas de nutrientes são mais pronunciadas na fase de desabastecimento do silo em comparação a fase de armazenamento. Além disso, um produto da combinação de inoculantes, contendo cepas homofermentativas e heterofermentativas, produz uma enzima esterase de ácido ferúlico, propõe quebrar as ligações entre a lignina e os carboidratos da parede celular e melhorar a digestão da fibra.

Por outro lado, além dos parâmetros fermentativos, o que permite conhecer as características de uma silagem é a digestibilidade e consumo voluntário, que resulta diretamente no desempenho animal, entretanto, silagens tratadas com inoculantes 
microbianos têm promovido benefícios variáveis na resposta animal (KUNG JR., 2001)

Esta revisão de literatura teve como objetivo discutir o efeito da utilização de inoculantes microbianos quanto aos parâmetros fermentativos, nutricionais, estabilidade anaeróbica e desempenho animal.

\section{Efeitos de aditivos biológicos sobre parâmetros fermentativos}

A fermentação consiste na conservação de carboidratos solúveis (CS) em ácidos orgânicos, pela ação de microrganismos, os quais prevalecem sob condições adequadas na composição da matéria seca ensilada (McDONALD et al., 1991). Com base no metabolismo de CS, as bactérias láticas podem ser classificadas como homofermentativas obrigatórias, que produzem ácido lático a partir de hexoses como a glicose; heterofermentativas facultativa, que produz tanto o ácido lático a partir de hexoses, quanto de pentoses e produz dióxido de carbono, etanol e/ou ácido acético; heterofermentativas obrigatórias que degradam hexoses e pentoses a ácido lático, acético e propiônico, entre outros (MUCK, 2010).

Segundo Bolsen et al. (2000) nos inoculantes comerciais homofermentativo há uma mistura de enzimas (celulases, hemicelulases e amilases) e bactérias (Lactobacillus plantarum, Streptococcus faecium e Pediococcus acidactili). Estudos na década de 90 lançaram no mercado consumidor os inoculantes contendo bactérias heterofermentativas, produtoras de ácido acético e propiônico, além do ácido lático, como Lactobacillus buchneri, Pediococcus cereviseae, Propianibacterium shermani e Propionibacterium acidipropionici, que têm sido avaliados buscando alterar o perfil da fermentação (RANJIT; et al., 2000).

$\mathrm{O}$ uso de inoculante objetiva favorecer a fermentação com produção mais eficiente de ácidos orgânicos, acelerar a queda do $\mathrm{pH}$ e inibir fermentações indesejáveis que deterioram a silagem, como a degradação protéica por Clostridium (KUNG JR.; RANJIT, 2001). Dessa forma, o benefício do inóculo na silagem pode ser avaliado pelo $\mathrm{pH}$ e pelos produtos finais da fermentação, como ácidos orgânicos e nitrogênio amoniacal.

Nesse sentido, Bolsen et al. (2000) e Santos et al. (2008) relataram que inoculantes melhoram os parâmetros fermentativos. Dessa maneira, os efeitos de inoculantes microbianos nas ensilagens de aveia (Avena strigosa) (BERTO; MÜHLBACH, 1997), de alfafa (Medicago sativa L.) (MAGALHÃES; RODRIGUES, 2004) e sobre as silagens de milho (Zea mays L.), foram estudados, sendo observada redução no $\mathrm{pH}$ das mesmas quando inoculada. Segundo Ávila (2007) os valores de $\mathrm{pH}$ nas silagens inoculadas de cana-de-açúcar (Saccharum officinarum) com inoculante heterofermentativo foram inferiores ao controle, 3,98 contra 3,88, fruto da maior eficiência de conversão de carboidratos solúveis em ácidos orgânicos.

Segundo McDonald et al. (1991), a proteólise se estende durante a fermentação quando não ocorrem condições suficientes para que os microrganismos indesejáveis sejam eliminados. Para Berto e Mühlbach (1997) o efeito dos inoculantes homofermentativos na ensilagem de aveia preta, causou redução o nitrogênio amoniacal (N-NH3) de 11,4 no controle para 9,7 e $9,1 \%$ do $\mathrm{N}$ total para o inóculo bacteriano e enzimático, respectivamente. De maneira semelhante, 
Rangrab et al. (2000) na ensilagem de alfafa, o tratamento enzimático determinou menores teores de N-NH3.

Já Ávila (2007) observou variação nas concentrações de N-NH3 que foram maiores para as silagens com inoculantes heterofermentativos comercial $(51,3 \%)$, seguido pela silagem controle $(39,95 \%)$ e pela silagem inóculo heterofermentativo isolado de cana-de-açúcar $(29,0 \% \mathrm{~N}$ total).

Magalhães e Rodrigues (2004) observaram que a inoculação de bactérias homoláticas influenciou o perfil fermentativo da silagem de alfafa, aumentando a concentração de ácido lático de 2,1 para 4,5\% na matéria seca (MS), em relação ao controle. Quanto à aplicação de inoculantes com bactérias heterofermentativas tem resultado em silagens com 3,6 a 5,0\% de ácido acético na MS (RANJIT; et al., 2000).

As enzimas são incluídas nos inoculantes, na tentativa de aumentar a disponibilidade de substrato para as bactérias produtoras de ácido lático, pela degradação de carboidratos complexos em CS (MUCK e KUNG JR., 1997). Segundo Muck (1996), um dos efeitos esperados dos inoculantes é o maior consumo de hemicelulose. Dessa forma, Berto e Mühlbach (1997), na ensilagem de aveia, Magalhães e Rodrigues (2004), alfafa e Loures (2004) capim mombaça (Panicum maximum Jacq. cv. Mombaça) e Santos et al. (2008) capim elefante (Pennisetum purpureum Schum), observaram que a inoculação reduziu a hemicelulose. No entanto, na ensilagem de forrageiras com baixo teor de CS, menos de $20 \%$ na MS, torna a forragem no estado fresco, um desafio para um aditivo estimulador da fermentação (MÜHLBACH, 1999).

Paziani (2004) avaliando silagem de capim tanzânia (Panicum maximum Jacq. cv. Tanzania), observaram efeitos favoráveis no uso de aditivos microbianos somente quando relacionado ao efeito do teor de MS para material ensilado. Já Patrizi et al. (2004) testaram três aditivos biológicos comerciais nas ensilagens de capim elefante, e observaram que apenas um aditivo foi eficiente em reduzir o $\mathrm{pH}$, demonstrando que nem todos os microrganismos são fermentadores ativos para determinadas espécies forrageiras. Dessa forma, o teor de CS, a alta disponibilidade de água e a especificidade da cultura restringem a efetividade das enzimas e bactérias.

Por outro lado, investigações realizadas por Pedroso et al. (2000), Igarasi (2002), Restle et al. (2003), Coan et al. (2005), Rocha et al. (2006) e Pereira et al. (2007), avaliando silagens de gramíneas tropicais, não observaram diferenças significativas entre silagens com e sem inoculantes, não sendo observada eficiência dos inoculantes para melhorar o padrão fermentativo das silagens.

Nesse aspecto, entre as prováveis explicações para as falhas nos inóculos, seria que as cepas de inoculantes derivam de espécies isoladas de plantas oriundas do hemisfério norte e lá são usados, principalmente, associadas a forragens emurchecidas contendo teores de MS superiores a 30\% (MÜHLBACH,2000), mantendo maior eficiência quando utilizados nessas culturas com adequado teor de MS. Já no hemisfério sul, respostas positivas ao uso de inoculantes têm sido alcançadas, quando as forrageiras são ensiladas com níveis adequados de CS, sugerindo que as limitações não são decorrentes somente da especificidade e teor de MS, mas também nas reduzidas concentrações de CS (SOLLENBERGER et al., 2004).

Nesse contexto, há questionamentos sobre o uso de inóculos microbianos, pois, as condições de estudo variam significativamente 
quanto à especificidade do inoculante à cultura, competição da flora epifítica, conteúdo de MS e CS. Dessa forma, o efeito do uso de aditivos biológicos encontra-se condicionados tanto a viabilidade biológica do inoculante, quanto às características intrínsecas da planta a ser ensilada.

\section{Efeito dos inoculantes biológicos na qualidade nutricional}

Bolsen et al. (2000) e Kung Jr. e Ranjit (2001), relataram que há melhoria do valor nutricional de silagens inoculadas com diferentes cepas de bactérias e enzimas, apresentando uma fração fibrosa inferior daquelas não aditivadas.

Nesse aspecto, Santos et al. (2008) avaliando diferentes ativações de inoculantes na ensilagem de capim tanzânia, observaram redução na fibra em detergente neutro (FDN) de 67,39 (controle) para 65,4 e $63,8 \%$ na MS, para a inoculação em água e inoculação em leite desnatado reconstituído a $10 \%$, respectivamente. Para Rangrab et al. (2000) a adição de lactobacilos mais enzimas, melhoraram a qualidade bromatológica das silagens de alfafa, diminuindo o teor de FDN. Já Siqueira et al (2005), constataram baixos valores de FDN em silagens de cana-de-açúcar tratadas com L. buchneri em comparação aos valores obtidos na silagem controle, $66,7 \%$ e $75,1 \%$ de MS, respectivamente.

Por outro lado, Igarasi (2002), Paziani (2004), Magalhães e Rodrigues (2004), Coan et al. (2005), Rocha et al. (2006) e Pereira et al. (2007), o uso de inoculantes microbianos não proporcionou aumento na qualidade da fração fibrosa. Kung Jr. e Ranjit (2001) e Queiroz (2006), investigando os efeitos de inóculos heterofermentativos sobre o valor nutricional de silagens, também constataram que o inóculo não modificou o teor de FDN em relação ao tratamento controle. Contudo, Pedroso et al. (2000), avaliando silagens de cana-de-açúcar, quanto aos parâmetros nutricionais, as silagens tratadas mostraram níveis mais elevados de FDN, 41,3 contra 39,1\% da MS e fibra em detergente ácido (FDA), 24,9 contra 22,5\% da MS. De maneira semelhante, Berto e Mühlbach (1997), observaram no tratamento com inoculante bacteriano níveis mais elevados de FDN, 51,3 contra 45,5\% da MS.

Segundo Bolsen et al. (2000), em revisão de literatura, os inoculantes bacterianos aumentaram significativamente a digestibilidade da fibra na maioria dos experimentos revisados, entretanto, não encontraram explicação para o fato, uma vez que as bactérias ácido láticas não são conhecidas por sua capacidade em degradar a parede celular das forrageiras ou outros componentes que limitam a digestibilidade dos volumosos para os ruminantes. Para Van Soest (1994), alterações na fração fibrosa são observadas normalmente, quando contém cepas de microrganismos fibroliticos, embora a ausência de resposta seja comumente observada. A ausência de efeito de inoculantes contendo enzimas fibrolíticas sobre a fração fibrosa das silagens pode ser atribuída à seleção de enzimas apropriadas a cada cultura, ao valor de $\mathrm{pH}$ ótimo para a ação destas não deve ser menor do que 4 e temperatura em torno de $50^{\circ} \mathrm{C}$ (KUNG JR. et al., 2003).

Segundo Van Soest (1994) a fração fibrosa do material ensilado pode ser acrescida percentualmente, em decorrência do decréscimo dos CS no processo fermentativo ou refermentativo, no qual os CS são reduzidos proporcionalmente ao aumento nos constituintes da parede celular, uma vez 
que fazem parte da planta, o aumento de um implica na diminuição do outro. Dessa forma, a não alteração na fração fibrosa da silagem aditivada pode ser justificada quando os carboidratos não representam uma fração significativa da planta, ou quando há eficácia do aditivo em preservar os carboidratos. Contudo, silagens nas quais o teor de CS é muito alto, mesmo que exista uma baixa eficácia do aditivo, essa pode resultar numa diminuição no teor de fibra em função de altas recuperações de MS (QUEIROZ, 2006).

Chen et al. (1994) relataram que há divergências entre silagens produzidas em silos laboratoriais e silos comerciais. Assim, o produto obtido pode não refletir o processo de armazenamento em escala comercial. Concordando com estes resultados, Sheperd e Kung Jr. (1996) observaram melhoria na fração fibrosa em silagens contendo inoculante em silos laboratoriais, entretanto, não constataram o mesmo efeito em silos comerciais. Já Rodrigues et al. (2002) observaram que silagens produzidas em silos laboratoriais proporcionam fermentação semelhante á aquela obtida em silos comerciais, quando a planta ensilada apresenta fácil fermentação, porém, a mesma situação não foi constatada quando a forragem apresentou difícil fermentação.

Com base nas literaturas de Igarasi (2002), Paziani (2004), Magalhães e Rodrigues (2004), Coan et al. (2005), Rocha et al. (2006) e Pereira et al. (2007) evidenciase que embora pesquisas demonstrem efeitos benéficos da utilização de inoculantes sobre a qualidade nutricional de silagens, ainda, há relatos de literatura que mostram resultados contraditórios e que questionam a economicidade desses aditivos na ensilagem para incrementar o valor nutritivo do volumoso conservado.

\section{Inóculos biológicos para estabilização sob aerobiose}

A utilizaçãode inoculantes na ensilagem sempre foi baseada em microrganismos homoláticos, apresentando como principais características, rápida redução do $\mathrm{pH}$ e alta produção de ácido lático (FILYA et al. 2004). No entanto, segundo Cai et al. (1999), silagens com altos níveis de ácido lático são mais suscetíveis à deterioração aeróbia. Dessa forma, aspectos até então considerados básicos para a conservação da silagem como, fermentação predominantemente homolática não são eficientes para evitar deterioração aeróbia das silagens.

Ranjit e KungJr. (2000) demonstraram que a exposição da silagem ao ar, microrganismos oportunistas como fungos, leveduras e bactérias aeróbias, produzem calor, consomem nutrientes e produtos finais da fermentação. Dessa forma, Kung Jr. (2001) definiu a estabilidade aeróbia da silagem como sendo o tempo observado para que a massa de forragem retirada do silo apresente elevação de temperatura em dois ${ }^{\circ} \mathrm{C}$, em relação à temperatura ambiente.

Segundo Ranjit e Kung Jr. (2000) inoculantes contendo cepas de bactérias heterofermentativas de L. buchneri, que produz ácido acético além do ácido lático, têm mostrado eficiência consistente na estabilidade aeróbia das silagens. Dessa forma, Ranjit e Kung Jr. (2000), Nishino et al. (2003) e Bernardes (2006) registraram aumento na estabilidade de silagens inoculadas com $L$. buchneri. Da maneira semelhante, Schimidt (2006) encontrou para os tratamentos de $L$. buchneri $10^{4}$ unidades formadoras de colônia/g (UFC/g) e L. buchneri com $10^{5} \mathrm{UFC} / \mathrm{g}$ da matéria verde $(\mathrm{MV})$, os maiores valores de estabilidade aeróbia, 14,4 e 55,2 horas, 
respectivamente, comparados com o controle - zero horas. Kleinchmit e Kung Jr. (2006) concluíram que em gramíneas a inoculação melhorou a estabilidade aeróbia em 20 horas nas silagens tratadas com $10^{5} \mathrm{UFC} / \mathrm{g}$ ou menos de L. buchneri e em 40 horas naquelas com mais de $10^{5} \mathrm{UFC} / \mathrm{g}$ na forragem.

Por outro lado, Queiroz (2006) não observou diferença no número de horas para se atingir a estabilidade aeróbia em silagens de cana-de-açúcar tratadas com L. buchneri e $L$. diolivorans. Para Pedroso (2003), os aditivos benzoato de sódio e L. buchneri melhoraram a estabilidade aeróbia das silagens, em relação ao tratamento controle, 78 e 72 horas contra 48 horas. Siqueira et al. (2007) concluíram que a associação de benzoato de sódio $\left(0,1 \%\right.$ da MV) e L. buchneri $\left(5 \times 10^{4} \mathrm{UFC} / \mathrm{g}\right)$ melhorou a estabilidade aeróbia, no período de 60 horas em comparação ao controle no período de 32 horas, entretanto, não diferiram dos tratamentos com inoculação de Propionibacterium sp. e L. plantarum $\left(1,5 \times 10^{5}\right.$ $\mathrm{UFC} / \mathrm{g})$ e adição de uréia ( $1,5 \%$ da MV).

Nesse sentido, estudos de Ranjite Kung Jr. (2000), Nishino et al. (2003), Kleinchmit e Kung Jr. (2006), Queiroz (2006) e Bernardes (2006) têm objetivado não só os aspectos fermentativos das forragens, mas também a estabilidade aeróbia das silagens, mostrando ser promissores os inoculantes contendo cepas das bactérias heterofermentativas.

\section{Desempenho animal versus uso de inoculantes biológicos}

McDonald et al. (1991), afirmaram que mudanças fermentativas não estão relacionadas diretamente a melhorias na digestibilidade e ao consumo de MS. Dessa maneira, Muck e Kung Jr. (1997) relataram que $60 \%$ dos inoculantes proporcionaram melhorias nos parâmetros fermentativos, entretanto, 33 e $28 \%$ dos experimentos observaram uma maior digestibilidade e consumo, respectivamente. Dessa forma, dietas contendo silagens tratadas com inoculantes microbianos têm promovido pequenos aumentos no consumo de MS e na digestibilidade de nutrientes (KUNG Jr., 2001).

Magalhães e Rodrigues (2003) observaram que silagens com inoculante tiveram aumento na digestibilidade aparente da MS, $81,7 \%$ contra 74,2\%, da FDN, 70,0\% contra $58,0 \%$, na FDA, $75,2 \%$ contra $63,9 \%$ e na $\mathrm{PB}, 83,1 \%$ contra $74,6 \%$ em relação a sem inoculante, porém, não observaram efeito do inóculo sobre o consumo de MS, que apresentou média de $13,9 \mathrm{~kg} / \mathrm{animal} / \mathrm{dia}$.

Bernardes et al. (2007) ao avaliarem o consumo e a digestibilidade de bovinos com inóculos homofermentativas e heterofermentativos, contendo silagem de capim marandu (Brachiaria brizantha $\mathrm{cv}$. Marandu), observaram que o consumo e a digestibilidade não foram afetados pelos tratamentos, com valores médios de 5,7 $\mathrm{kg} / \mathrm{dia}$ de MS e $51,3 \%$, respectivamente. De maneira semelhante, Silva et al. (2006), avaliaram o consumo e digestibilidade total do nutrientes em bovinos contendo silagem de milho e sorgo (Sorghum spp.) tratados com inoculante homofermentativo, a inoculação com o aditivo não influenciou o consumo, 6,6 kg/dia de MS e digestibilidade de 61,2\%, indicando que as dietas equivaleram-se nutricionalmente.

Ranjit et al. (2002) avaliaram o desempenho de ruminantes alimentados com silagens de milho e Schmidt et al. (2007) com silagem de cana-de-açucar tratadas com L. buchneri, observaram que nos tratamentos não houve diferença no consumo de MS. 
Resultados diferentes foram observados por Azevedo et al. (2007) nas silagens inoculadas com L. buchneri para a alimentação de vacas em lactação, que promoveram melhorias no consumo, 12,7 contra $11,4 \mathrm{~kg}$ MS/dia, em relação as silagens não inoculadas. Winters et al. (2001) avaliando silagens de gramíneas de inverno inoculadas, observaram maior consumo de MS, 8,2 contra 7,4 kg/dia, consequentemente, maior ganho de peso diário, 0,9 contra 0,7 $\mathrm{kg} /$ animal, respectivamente. Já Schmidt (2006), avaliando o desempenho de bovinos recebendo silagens de cana-de-açúcar com L. buchneri, observaram incremento no ganho de peso médio diário de $0,24 \mathrm{~kg} / \mathrm{animal} \mathrm{em}$ relação aos animais que receberam silagens não inoculadas. Porém, Restle et al. (2003) e Paziani (2004) com inoculantes homoláticos, utilizando silagens de gramíneas tropicais não registraram efeito da inoculação sobre o consumo de MS e ganho de peso médio diário.

Dessa forma, vários autores, entre eles Restle et al. (2003), Paziani (2004), Schmidt (2006), Azevedo et al. (2007) tentaram elucidar como as silagens produzidas com inoculantes microbianos resultam numa compensação positiva ao desempenho animal. Porém, pelo fato das dietas, contendo silagens inoculadas, apresentarem variações tanto na digestibilidade, quanto no consumo de MS, consequentemente, há inconstância no desempenho animal, que pode estar relacionado a variações diversas no inóculo e na forragem ensilada. Dessa forma, segundo Weinberg et al. (2004) conclui que não foram identificados de modo conclusivo se as silagens inoculadas com microrganismos podem trazer benefícios ao desempenho dos ruminantes.

\section{Considerações Finais}

Atualmente há um número crescente de estudos com inoculantes biológicos, porém, o uso de inoculantes biológicos é questionável, em virtude, principalmente, da viabilidade biológica do inóculo e das características intrínsecas da planta ensilada, entretanto, aditivos biológicos heterofermentativos, mostram-se promissores no controle da estabilidade aeróbia.

\section{Referências}

ÁVILA, C. L. S. Isolamento e uso de Lactobacillus buchneri na ensilagem de capimmombaça e cana-de-açúcar. 2007. 175f. Tese (Doutorado em Zootecnia) - Universidade Federal de Lavras, Lavras, 2007.

AZEVEDO, S. T.; PEREIRA, M. L. A.; SIGNORETTI, R. D.; SIQUEIRA, G. R.; RESENDE, F. D.; MENDONÇA, S. S.; GARCIA, T. S. Consumo e produção e composição do leite de vacas leiteiras alimentadas com silagem de cana-de-açúcar com e sem aditivo bacteriano.In: REUNIÃO ANUAL DA SOCIEDADE BRASILEIRA DE ZOOTECNIA, 44., 2007, Jaboticabal. Anais... Jaboticabal: SBZ/UNESP, 2007. CD-ROM.

BERNARDES, T. F. Controle da deterioração aeróbia de silagens. 2006. 103 f. Tese (Doutorado em Zootecnia) - Faculdade de Ciências Agrárias e Veterinárias, Universidade Estadual Paulista, Jaboticabal, 2006. 
BERNARDES, T. F.; REIS, R. A.; MONTEIRO, R. R.; AMARAL, R. C.; SIQUEIRA, G. R.; ROTH, A. P. T. P.; TOTH, M. T. P. Perdas no desabastecimento do silo, consumo e digestibilidade aparente da silagem de capim marandu tratado com inoculantes contendo bactérias homo e heterofermentativas. In: REUNIÃO ANUAL DA SOCIEDADE BRASILEIRA DE ZOOTECNIA, 44., 2007, Jaboticabal. Anais... Jaboticabal: SBZ/ UNESP, 2007. CD-ROM.

BERTO,J.L.; MÜHLBACH,P.R. F. Silagem de aveia preta no estádio vegetativo, submetida ação de inoculantes e ao efeito do emurchecimento. Revista Brasileira de Zootecnia, Viçosa, v.26, n.4. p.651-658, 1997.

BOLSEN, K. K.; WILKINSON, M.; LIN, C. J. Biotechnology in feed industry: evolucion of silage and inoculants: proceses and prevention. In: Proceeding of Alltech's $16^{\text {th }}$., Annual Symposium, $16^{\text {th }} ., 2000$. Nottingham, UK. Proceedings... Nottingham University Press, 2000.

CAI, Y. Identification and characterization of Enterococcus species isolated from forage crops and their influence on silage fermentation. Journal of Dairy Science, Champaign, v.82, n.11, p.2466-2471, 1999.

CHEN, J; STOKES, M. R.; WALLACE, C. R. Effects of enzime-inoculant systems on preservation and nutritive value of hay crop and corn silage. Journal of Dairy Science, Savoy, v.77, n.2, p.501-512, 1994.

COAN, R. M.; VIEIRA, P. F.; SILVEIRA, R. N.; REIS, R. A.; MAGLEIROS, E. B.; PEREIRA, M. S. Inoculante enzimático-bacteriano, composição química e parâmetros fermentativos das silagens dos capins Tanzânia e Mombaça. Revista Brasileira de Zootecnia, Viçosa, v.34, n.2, p.416-424, 2005.

FILYA, I.; SUCU, E.; KARABULUT, A. The effect of Propionibacterium acidipropionici, with or without Lactobacillus plantarum, on the fermentation and aerobic stability of wheat, sorghum and maize silages. Journal Applied Microbiology, v.97, p.818-821, 2004.

IGARASI, M. S. Controle de perdas na ensilagem de capim Tanzânia (Panicum maximum Jacq. Cv. Tanzânia) sob os efeitos do teor de matéria seca, do tamanho de partícula, da estação do ano e da presença do inoculante bacteriano. 2002.151 f. Dissertação (Mestrado em Agronomia) - Escola Superior Agrícola "Luiz de Queiroz", Universidade de São Paulo, Piracicaba, 2002.

KLEINCHMIT, D. H.; KUNG JR., L. A meta analysis of the effects of Lactobacillus buchneri on the fermentation and aerobic stability de corn and grass and small grain silages. Journal of Dairy Science, Savoy, v.89, n.10, p.4005-4013, 2006.

KUNG JR., L. Silage fermentation and additives. In: SCIENCE AND TECHNOLOGY IN THE FEED INDUSTRY. Proceedings... Alltech's $17^{\text {th }}$., Annual Symposium. Ed.T.P. Lyons and K.A. Jacques, 2001. 
KUNG JR., L.; RANJIT, N. K. The effect of Lactobacillus buchneri and other additives on the fermentation and aerobic stability of barley silage. Journal of Dairy Science, Savoy, v.84, n.5, p.1149-1155, 2001.

KUNG JR., L.; STOKES, M. R.; LIN, C.J. Silage additives. In: BUXTON, D.R.; MUCK, R.E.; HARRISON,J.H. (Ed.) Silage science and technology. Madison: American Society of Agronomy, Crop Science Society of America, Soil Science Society of America, 2003. p.251-304.

KUNG Jr., L. Effects of microbial additives in silages: facts and perspectives. In: ZOPOLLATTO, M.; MURARO, G.B.; NUSSIO, L.G. (Ed.). International symposium on forage quality and conservation, São Pedro, 2009. Proceedings...Piracicaba: FEALQ, 2009. v. 1, p.7-22.

LOURES, D. R. S. Enzimas fibrolíticas e emurchecimento no controle de perdas da ensilagem e na digestão de nutrientes em bovinos alimentados com rações contendo silagem de capim Tanzânia. 2004. 132 f. Tese - (Doutorado em Agronomia) - Escola Superior de Agricultura Luiz de Queiroz, Piracicaba, 2004.

MAGALHÃES, V. J. A.; RODRIGUES, P. H. M. Inoculação microbiana da silagem présecada de alfafa sobre a digestibilidade aparente da dieta por vacas leiteiras. Acta Scientiarum, Maringá, v.25, n.1, p.165-169, 2003.

MAGALHÃES, V. J. A.; RODRIGUES, P.H.M. Avaliação de inoculante microbiano na composição bromatológica, fermentação e estabilidade aeróbia de silagem pré-seca de alfafa. Revista Brasileira de Zootecnia, Viçosa, v.33, n.1, p.51-59, 2004.

McDONALD, P.; HENDERSON, A. R.; HERON, S. J. E. The biochemistry of silage. 2.ed. Marlow: Chalcomb Publishing, 1991.340 p.

MUCK, R. E. Silage inoculation: inoculation of silage and its effects on silage quality. In: Conference With Dairy and Forage Industries. Proceedings... Madison, U.S., 1996. p.43-51.

MUCK, R. E.; KUNG JR, L. Effects of silage additives on ensiling. In: SILAGE: FIELD TO FEEDBUNK, Ithaca, 1997. Proceedings... Ithaca: NRAES, 1997. p.187-199.

MUCK, R. E. Silage microbiology and its control through additives. Revista Brasileira de Zootecnia, Viçosa, v.39, p. 183-191, 2010.

MÜHLBACH, P. R. F. Silagem: Produção com controle de perdas. In: LOBATO, J.F. P. L.; BARCELLOS, J. O. J.; KESSLER, A. M. Produção de Bovinos de Corte. Porto Alegre: EDI-PUCRS, 1999. 346 p.

MÜHLBACH, P. R. F. Additives to improve the silage making process with tropical forages. In: FAO ELECTRONIC CONFERENCE ON TROPICAL SILAGE, Rome, 1999. Proceedings... Rome: FAO, 2000. p.151-164. 
NISHINO, N.; YOSHIDA, M.; SHIOTA, H.; SAKAGUCHI. Accumulation of 1,2-propanediol and enhancement of aerobic stability in whole crop maize silage inoculated with Lactobacillus buchneri. Journal of Applied Microbiology, Oxford, v.94, n.5, p.800807, 2003.

PATRIZI, W. L.; MADRUGA JÚNIOR, C. R. F.; MINETTO, T. P.; NOGUEIRA, E.; MORAIS, M. G. Efeito de aditivos biológicos comerciais na silagem de capim Elefante (Pennisetum purpureum Schum). Arquivo Brasileiro de Medicina Veterinária e Zootecnia, Belo Horizonte, v.56, p.392-397, 2004.

PAZIANI, S. F. Controle de perdas na ensilagem, desempenho e digestão de nutrientes em bovinos de corte alimentados com rações contendo silagens de capim tanzânia. 2004. 208f. Tese (Doutorado em Agronomia) - Escola Superior de Agricultura "Luiz de Queiroz", Universidade de São Paulo, Piracicaba, 2004.

PEDROSO, A.F.; FREITAS, A. R.; SOUZA, G. B. Efeito de inoculante bacteriano sobre a qualidade da silagem e perda de matéria seca durante a ensilagem de sorgo. Revista Brasileira de Zootecnia, Viçosa, v.29, n.1, p.48-52, 2000.

PEDROSO, A. F. Aditivos químicos e microbianos no controle de perdas e na qualidade de silagem de cana-de-açúcar (Saccharum officinarum L.). 2003.120f. Tese (Doutorado em Agronomia) - Escola Superior de Agricultura Luiz de Queiroz, Universidade de São Paulo, Piracicaba, SP, 2003.

PEREIRA, O. G.; ROCHA K. D.; FERREIRA, C. L. L. F. Composição química, caracterização e quantificação da população de microrganismos em capim-elefante cv. Cameroon (Pennisetum purpureum, Schum.) e suas silagens. Revista Brasileira de Zootecnia, Viçosa, v.36, n.6, p.1742-1750, 2007.

QUEIROZ, O. C. M. Associação de aditivos microbianos na ensilagem e o desempenho de vacas em lactação recebendo silagem de cana-de-açúcar comparada a um volumoso tradicional. 2006. 122 f. Tese (Doutorado em Agronomia) - Escola Superior de Agricultura "Luiz de Queiroz", Universidade de São Paulo, Piracicaba, 2006.

RANJIT, N. K.; TAYLOR, C. C.; KUNG JR., L. Effect of Lactobacillus buchneri 40788 on the fermentation, aerobic stability and nutritive value of maize silage. Grass and Forage Science, v.57, n.1, p.73-81, 2002.

RANGRAB, L. H.; MÜHLBACH, P. R. F.; BERTO, J. L. Silagem da alfafa colhida no início do florescimento e submetido ao emurchecimento e à ação de aditivos biológicos. Efeitos da adição de inoculantes microbianos sobre a composição bromatológicos. Revista Brasileira de Zootecnia, Viçosa, v.29, n.2, p.349-356, 2000.

RANJIT, N. K.; KUNG JR, L. The effect of Lactobacillus buchneri, Lactobacillus plantarum, or a chemical preservative on the fermentation and aerobic stability of corn silage. Journal of Dairy Science, Savoy, v.83, n.3, p.526-535. 2000. 
RESTLE,J.; NEUMANN,M.; BRONDANI,I.L.; GONÇALVES,J.M.; PELLEGRINI, L. G. Avaliação de silagem de capim papuã (Brachiaria plantaginea) por meio do desempenho de bezerros de corte confinados. Ciência Rural, Santa Maria, v.33, n.4, p.749-756, 2003.

ROCHA, K. D.; PEREIRA, O. G.; VALADARES FILHO, S. C.; OLIVEIRA, A. P.; PACHECO, L. B. B.; CHIZZOTTI, F. H. M. Valor nutritivo de silagens de milho (Zea mays L.) produzidas com inoculantes enzimo-bacterianos. Revista Brasileira de Zootecnia, Viçosa, v.35, n.2, p.389-395, 2006.

RODRIGUES, P. H. M.; SENATORE, A. L.; ANDRADE, S. J. T.; RUZANTE, J. M.; LUCCI, C. S.; LIMA, F. R. Efeitos da adição de inoculantes microbianos sobre a composição bromatológica e perfil de fermentativo da silagem de sorgo produzida em silos experimentais. Revista Brasileira de Zootecnia, Viçosa, v.31, n.6, p.2373-2379, 2002.

SANTOS, E. M.; ZANINE,A. M.; FERREIRA.D.J.; OLIVEIRA,J. S.; PENTEADO,D. C. S.; PEREIRA, O. G. Inoculante ativado melhora a silagem de capim-tanzânia. Archivos de Zootecnia, Córdoba, v.57, n.217, p.35-42, 2008.

SCHMIDT, P.; MARI, L. J.; NUSSIO, L. G.; PEDROSO, A. F.; PAZIANI, S. F.; WECHSLER, F.S. Aditivos químicos e biológicos na ensilagem de cana-de-açúcar. 1. Composição química das silagens, ingestão, digestibilidade e comportamento ingestivo. Revista Brasileira de Zootecnia, Viçosa, v.36, n.5, p.1666-1675, 2007.

SCHMIDT, P. Perdas fermentativas na ensilagem, parâmetros disgestivos e desempenho de bovinos de corte alimentados com rações contendo silagens de cana-de açúcar. 2006. 228 f. Tese (Doutorado em Agronomia) - Escola Superior de Agricultura Luiz de Queiroz. Universidade de São Paulo, USP, Piracicaba, 2006.

SHEPERD, A.C.; KUNG, L. Effect of enzyme additive on composition of corn silage ensiled at various stages of maturity. Journal of Dairy Science, Savoy, v.79, n.10, p.1767-1773, 1996.

SILVA, A. V.; PEREIRA, O. G.; VALADARES FILHO, S. C.; GARCIA, R.; CECON, P. R.; FERREIRA, C. L. L. F. Consumo e digestibilidades dos nutrientes em bovinos recebendo dietas contendo silagens de milho e sorgo, com e sem inoculante microbiano. Revista Brasileira de Zootecnia, Viçosa, v.35, n.6, p.2469-2478, 2006.

SIQUEIRA. J. L.; QUEIROZ, O. C. M.; NUSSIO, L. G. Desenvolvimento de Aditivos Microbianos para Ensilagem: Realidade e Perspectivas. In: Ricardo Andrade Reis; Gustavo Rezende Siqueira; Liandra M. A. Bertipaglia; Amanda Prates Oliveira; Gabriel M. P. de Melo; Thiago Fernandes Bernardes. (Org.). Volumosos na Produção de Ruminantes. 1 ed. Jaboticabal: Funep, 2005.v.1, p.1-24.

SIQUEIRA, G. R.; REIS, R. A.; SCHOCKEN-ITURRINO, R. P.; BERNARDES, T. F.; PIRES, A. J. V.; ROTH, M. T. P.; ROTH, A. P. T. P. Associação entre aditivos químicos e bacterianos na ensilagem de cana-de-açúcar. Revista Brasileira de Zootecnia, Viçosa, v.36, n.4, p.789-798, 2007. 
SOLLENBERGER, L.E.; REIS, R. A.; NUSSIO, L. G.; CHAMBLISS, C. G.; KUNKLE, W.. Conserved forage. In: MOSER, L.E.; BURSON, B. L.; SOLLENBERGER, L.E.(Ed.) Warm season grasses. Madison: American Society of Agronomy, Crop Science Society of America, Soil Science Society of America, 2004. p.355-387.

VAN SOEST, P. J. Nutritional ecology of the ruminant. 2.ed. Ithaca: Cornell University Press, 1994. 476p.

WEINBERG, Z. G.; CHEN, Y.; GAMBURG, M. The passage of lactic acid bacteria from silage into rumen fluid, in vitro studies. Journal of Dairy Science, Savoy, v.87, n.10, p.3386-3397, 2004.

WINTERS, A. L.; FYCHAN, R.; JONES, R. Effect of formic acid and a bacterial inoculant on the amino acid composition of grass silage and on animal performance. Grass and Forage Science, v.56, n.2, p.181-192, 2001.

ZOPOLLATTO, M.; DANIEL, J. L. P.; NUSSIO, L. G. Aditivos microbiológicos em silagens no Brasil: revisão dos aspectos da ensilagem e do desempenho de animais. Revista Brasileira de Zootecnia, Viçosa, v.38, Suplemento Especial, p.170-189, 2009. 